\title{
Variação do Equilíbrio Muscular Durante uma Temporada em Jogadores de Futebol Categoria Sub-20
}

\section{Variation of the Muscular Balance During a Season in Under-20 Soccer Players}

Luiz Fernando Goulart' ${ }^{1}$

Raphael Mendes Ritti Dias ${ }^{2,4}$

Leandro Ricardo Altimari ${ }^{3,4}$

1. Departamento de Futebol

Profissional da Associação Atlética Ponte Preta. Campinas, São Paulo, Brasil.

2. Programa de pós-graduação

em Saúde Pública.

Faculdade de Saúde Publica. Universidade de São Paulo, São Paulo, Brasil. Bolsista FAPESP processo 06/00759-3

3. Programa de pós-graduação em Educação Física.

Faculdade de Educação Física. Universidade de Campinas, São Paulo, Brasil. Bolsista FAPESP processo 05/00151-2

4. Grupo de Estudo e Pesquisa em Metabolismo, Nutrição e Exercício.

Centro de Educação Física e

Desportos.Universidade Estadual de Londrina, Paraná, Brasil.

\section{Endereço para correspondência:}

Raphael Mendes Ritti Dias

Av. Eng. Heitor Antônio Eiras Garcia, 79 ap 44, bl B

Butantã - São Paulo - SP

CEP- 05588-000

E-mail: rdias@usp.br

Submetido em 30/10/2006

Versão final recebida em 12/02/2007 Aceito em 17/07/2007

\begin{abstract}
RESUMO
O objetivo deste estudo foi analisar o equilíbrio muscular dos flexores e extensores (RFE) de joelho ao longo de uma temporada de treinamento em jogadores de futebol categoria sub-20. Fizeram parte da amostra 15 sujeitos pertencentes à equipe sub-20 da Associação Atlética Ponte Preta de Campinas. Os atletas participaram de um macrociclo de preparação (MP) de 29 semanas, composto por período preparatório e competitivo que foram divididos em quatro mesociclos: etapa geral (M1), etapa especial (M2), etapa pré-competitiva (M3) e etapa competitiva (M4). A RFE de ambos os membros foi determinada em dinamômetro isocinético utilizando o pico de torque (PT) obtido em três séries consecutivas de cinco repetições com velocidade de 60\%/s. Avaliação isocinética foi realizada em quatro momentos ao longo do MP, sempre ao final de cada mesociclo (M1, M2, M3 e M4). Para análise estatística, foi empregado teste Friedman de medidas repetidas, seguida do teste de Wilcoxon e teste $U$ de Mann-Whitney, com nível de significância de $p<0,05$. O PT nos músculos flexores de joelho, em ambos os membros, no M2 e M3 foram superiores aos observados em M1 e M4. O PT dos extensores de joelho em M1 foi significantemente inferior aos demais momentos do estudo (M2, M3 e M4), em ambos os membros. A RFE, em ambos os membros, foi inferior em M1 quando comparado a M2 e M3. A comparação da RFE entre os membros não revelou diferenças significantes em nenhum dos momentos do estudo ( $M 1, M 2, M 3$ e M4). Os resultados encontrados na presente investigação indicaram existência de alterações na magnitude da RFE, porém dentro da normalidade, e, manutenção da proporcionalidade entre os membros ao longo do MP. Esses resultados sugerem que não existem períodos sensíveis para a ocorrência de lesões em virtude de desequilíbrios musculares ao longo do MP em jogadores de futebol da categoria sub-20.
\end{abstract}

Palavras-chave: avaliação isocinética, agonista, antagonista, treinamento.

\section{ABSTRACT}

The objective of the present study was to evaluate the muscular balance of knee flexors and extensors (RFE) in under-20 soccer players during a training season. 15 under-20 subjects from the Ponte Preta Athletic Association of Campinas participated in a 29 week macrocycle preparation (MP), composed of preparatory and competitive periods which were divided into four mesocycles: general stage (M1), special stage (M2), pre-competitive stage (M3) and competitive stage (M4). RFE of both members was determined with the torque peak (TP) obtained in isokinetic dynamometer in three consecutive sets of five repetitions of 60 degrees/s. Isokinetic evaluation was accomplished in four stages along the MP at the end of each mesocycle (M1, M2, M3, and M4). Statistic analysis was performed using the Friedman test with repeated measures, followed by Wilcoxon test and Mann-Whitney $U$ test, with significance level of $p<0.05$. TP of knee flexors muscles in both members were greater in $M 2$ and $M 3$ than in M1 and M4. TP of knee extensors in M1 was significantly inferior than the other stages of the study (M2, $\mathrm{M} 3$, and M4), in both members. RFE, in both members, was inferior in M1 when compared to M2 and M3. RFE comparison among members did not reveal significant differences in any moment of the study (M1, M2, M3, and M4). The results indicated the existence of alterations in the size of RFE; within normality though, and maintenance of the proportionality among members along the MP. These results suggest that there are not sensitive periods to the occurrence of injuries due to muscular imbalances along MP in under-20 soccer players.

Keywords: isokinetic evaluation, agonist, antagonist, training.

\section{INTRODUÇÃO}

O futebol é um dos esportes mais populares do mundo, com mais de 240 milhões de praticantes em 2000 (1). No tocante às exigências fisiológicas, o futebol é caracterizado por ações motoras intermitentes de curta duração e alta intensidade, que variam com períodos de ações motoras de maior duração e menor intensidade(2).

Segundo Rahnama et al. ${ }^{(3)}$ tanto a prática competitiva, como o treinamento no futebol, apresentam altas taxas de incidência de lesões e alto percentual de atletas lesionados, principalmente nos membros inferiores. Essas taxas são superiores às observadas em outros esportes de contato como hockey, handebol, basquetebol, rugby, judô e boxe ${ }^{(4)}$. No entanto, apesar de existir tendência em associar o contato físico no futebol com a ocorrência de lesões, existem evidências de que a maioria das lesões no futebol ocorre em ações motoras que não envolvem contato físico, como a corrida, o chute, as trocas de direções e os saltos ${ }^{(1)}$.

Por outro lado, alguns autores verificaram que a ocorrência de lesões em atletas está relacionada ao treinamento e à prática esportiva, que resultam no desenvolvimento específico da musculatura de acordo com as exigências da modalidade praticada (1). Essa especialização, por sua vez, pode promover o desequilíbrio entre as forças estáticas e 
dinâmicas nas articulações, na postura, e na mecânica articular, aumentando, assim, a predisposição para ocorrência de lesões ${ }^{(5)}$.

Nesse sentido, a relação de equilíbrio muscular de flexores e extensores (RFE) tem sido utilizada para examinar a habilidade funcional das articulações e instabilidade do ligamento cruzado anterior, fornecendo um indicador sobre o risco de lesões em indivíduos de diferentes populações $^{(5,6)}$. Mais especificamente no futebol, essa razão é obtida na maioria das vezes por meio dos valores força da articulação do joelho(7). Para tanto, a mensuração da força muscular é realizada em dinamômetro isocinético, pois esse método permite quantificar, em valores absolutos, alguns indicadores da função muscular, como o pico de torque (PT), utilizado no cálculo da RFE. Para análise dos resultados, geralmente os valores individuais são contrastados com valores de referência propostos na literatura, valores considerados normais para essa relação variam entre $50 \%$ e $80 \%$ para a população em geral ${ }^{(8)}$ e, aproximadamente, $65 \%$ em jogadores de futebol $\left.\right|^{(7)}$.

Apesar de alguns estudos transversais verificarem a RFE de joelho em atletas de futebol, estudos longitudinais, com propósito de analisar o comportamento desta variável não tem sido alvo de publicações e elucidações no que concerne tanto ao futebol brasileiro, como ao futebol internacional. Essa informação é de extrema importância, haja vista que o acompanhamento deste índice ao longo de uma temporada de treinamento, poderia fornecer ferramentas importantes para a estruturação do treinamento de força dentro do macrociclo de preparação (MP), além de auxiliar na adoção de condutas preventivas ao longo da temporada. Sendo assim, o objetivo do presente estudo foi acompanhar a RFE de joelho ao longo de uma temporada de treinamento em jogadores de futebol da categoria sub-20.

\section{MÉTODOS}

\section{Amostra}

Fizeram parte da amostra, inicialmente, 23 sujeitos pertencentes à equipe sub-20 da Associação Atlética Ponte Preta, da cidade de Campinas, São Paulo, que tinham idade entre 17 e 20 anos e tempo de prática na modalidade entre quatro e seis anos. Cinco desses sujeitos acabaram não concluindo o experimento por terem saído do clube, e três, por motivos de lesões (um com lesão no púbis e dois com lesão no tornozelo). Ressalta-se que esses sujeitos deixaram de fazer parte do grupo experimental na etapa de preparação especial do macrociclo de treino. Assim, apenas 15 indivíduos completaram o experimento, sendo que esses participaram de todas as avaliações em todas as etapas do presente estudo. A comparação dos valores de RFE obtidos após a etapa de preparação geral dos indivíduos que concluíram o experimento (G1), dos que deixaram o clube (G2) e dos que foram excluídos por lesão (G3) são apresentados na sessão de resultados.

Os indivíduos, após serem esclarecidos sobre as finalidades do estudo e os procedimentos aos quais seriam submetidos, assinaram um termo de consentimento livre e esclarecido. Este estudo foi aprovado pelo Comitê de Ética em Pesquisa da Universidade de filiação do autor.

\section{Mensuração dos parâmetros de avaliação isocinética}

Para a avaliação isocinética concêntrica da musculatura flexora e extensora de joelho foi utilizado dinamômetro isocinético da marca Cybex" modelo Norm ${ }^{\text {tm }} 6000$ (CSMI, USA). Para o posicionamento do avaliado no dinamômetro isocinético, preparação e calibração do equipamento seguiram-se as orientações do manual de padronização, Sistema de Teste e Reabilitação fornecido pelo fabricante. Os parâmetros isocinéticos foram obtidos por programa computadorizado (HUMAC/CYBEX NORM"', USA) que permitiu a determinação do PT em relação à massa corporal total (\% $M C$ ) do avaliado (equação 1).

$$
\text { (equação 1) } \% \mathrm{MC}=\frac{\text { valor puro do parâmetro }}{\text { massa corporal total }} \times 100
$$

Previamente ao início do estudo, e com intervalo de 48 horas da última sessão de treinamento, foi empregado protocolo de familiarização na tentativa de reduzir os efeitos de aprendizagem e estabelecer a reprodutibilidade do teste. Todos os sujeitos foram testados em situação semelhante ao protocolo experimental, em duas sessões distintas, intervaladas por períodos de cinco dias. Os coeficientes de correlação intra-classe encontrados foram de 0,98 e 0,97 para aos músculos flexores de joelho direito e esquerdo, respectivamente, e 0,98 para ambos os membros nos músculos extensores de joelho.

A sessão de testes foi realizada com intervalo de dois dias da última sessão de familiarização e $24 \mathrm{~h}$ da última sessão de treinamento. Os indivíduos foram orientados a não realizarem atividades físicas vigorosas durantes este período. As sessões de testes durante a temporada de treinamento sempre foram realizadas no mesmo horário do dia (manhã). Além disso, as variáveis de temperatura ambiente e umidade relativa do ar foram mantidas entre 22 e $24^{\circ} \mathrm{C}$ e 50 e $60 \%$ respectivamente.

O PT concêntrico dos músculos flexores e extensores de joelho foi obtido em ambos os membros, em três séries consecutivas de cinco repetições, com velocidade de $60 \%$ s. O intervalo adotado entre as séries foi de 30 segundos $^{(9)}$.

O protocolo consistiu inicialmente de aquecimento com dez minutos de duração em cicloergômetro mecânico para membros inferiores (JOHNSON JPC ${ }^{\circledR} 5100$, UK). A carga utilizada foi de 0,5kpm e cadência de pedaladas de 70rpm. Em seguida, os sujeitos realizaram alongamento ativo dos membros inferiores (quadríceps, isquiopoplíteos e tríceps sural), musculatura paravertebral, quadrado lombar e membros superiores com duração de cinco minutos. Embora os estudos na literatura indiquem que a realização de alongamento previamente a execução de exercícios de força promovem redução no desempenho da força ${ }^{(10,11)}$, este procedimento era praticado no início de todas as sessões de treinamento desses atletas. Assim, foi feita a opção pela manutenção deste procedimento, haja vista que foi empregado sistematicamente nos diferentes momentos do estudo.

Posteriormente, os indivíduos foram acomodados na cadeira do aparelho, na posição sentada, com inclinação do tronco de aproximadamente $80^{\circ}$ e as coxas apoiadas no acento. O braço de alavanca do dinamômetro foi posicionado paralelamente à perna do jogador com uma almofada de resistência fixada distalmente, alinhando o eixo do aparelho com o eixo do joelho.

A estabilização dos atletas na cadeira do dinamômetro foi realizada por meio de cintos fixados no tórax, quadril e coxa do membro a ser testado, ficando o outro membro fixo por um cinto adaptado à cadeira. Em seguida, foi realizada correção da força da gravidade ${ }^{(12)}$.

Durante o teste, os jogadores foram estimulados verbalmente. Além disso, os atletas recebiam retorno visual da atividade do grupo muscular testado por meio do monitor acoplado ao dinamômetro.

\section{Relação de equilíbrio muscular concêntrico entre flexores e extensores de joelho (RFE)}

A RFE dos membros direito e esquerdo ao longo da temporada foi obtida por meio do PT. Esse indicador foi escolhido por ser um indicador de força máxima ${ }^{(9,13)}$, capacidade física esta de extrema importância na prática do futebol(14).

\section{Modelo de periodização do treinamento utilizado ao longo temporada}

A preparação física dos atletas durante a temporada foi estruturada em um MP com duração de 29 semanas, composto por dois períodos: preparatório e competitivo (Figura 1).

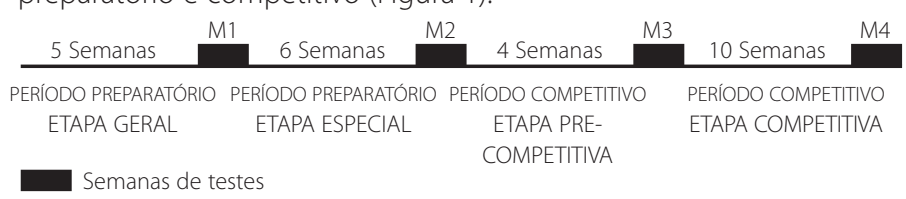

Figura 1. Delineamento do macrociclo de preparação. 
O MP foi estruturado a partir do sistema de treinamento em bloco proposto por Verkhoshansky ${ }^{(15)}$ e dividido em três etapas, sendo que em cada uma delas foi enfatizada uma capacidade física condicionante (resistência, força e velocidade), seguida de uma etapa de manutenção. Os testes foram realizados sempre ao final de cada etapa, e, para isso, foi separada uma semana entre os períodos (Figura 1).

O período preparatório foi subdividido em dois mesociclos de preparação: etapa geral e etapa especial. A etapa geral (M1) foi constituída de um mesociclo com duração de cinco semanas e teve objetivo de desenvolver a resistência em todas as formas de manifestação exigidas na prática do futebol (resistência aeróbia, resistência anaeróbia e resistência de força). Para o treinamento da resistência aeróbia foram realizadas corridas contínuas com distâncias de 4.000 a 5.000m, corridas intervaladas extensivas, com distâncias fixas de $1000 \mathrm{~m}$ e volume crescente a cada semana, com séries que variaram de quatro a seis, com intervalo de recuperação de 150-180s e corridas intervaladas intensivas, com distâncias entre 25 e 200m e volume crescente semanal, que variou de 10 a 30 séries, com intervalo de de 15-40s. O treinamento da resistência anaeróbia lática foi realizado em duas sessões semanais e foi executado a partir de circuito específico de dez estações onde os indivíduos realizaram exercícios pliométricos, acelerações e sprints curtos executados de forma acíclica em diferentes direções (movimentos para frente, lateral e costas) com tempo de execução de até 40 s. 0 intervalo de recuperação estabelecido entre as execuções das ações motoras nos circuitos foi de $3 \mathrm{~min}$. 0 treinamento da resistência de força foi aplicado por meio de treinamento com pesos em duas sessões semanais realizado em dias alternados. O programa de treinamento foi composto por cinco exercícios, a saber: flexão do joelho na mesa flexora, extensão do joelho na mesa extensora, extensão do quadril e extensão de joelho no leg press $45^{\circ}$, extensão de joelho no agachamento guiado, e flexão plantar no leg press. Os exercícios foram executados em forma de circuito, com volume crescente a cada semana, utilizando seis a nove séries de dez repetições e intensidade correspondente a 50 \% de uma repetição máxima. O intervalo de recuperação entre os exercícios foi de $60 \mathrm{~s}^{(16)}$.

A etapa especial (M2) foi composta por um mesociclo de seis semanas no qual foi enfatizado o desenvolvimento da força (força máxima e a força rápida). O treinamento da força máxima foi executado a partir de treinamento com pesos, sendo realizado durante as três primeiras semanas do mesociclo, em três sessões semanais em dias alternados. O volume foi crescente a cada semana, com quatro a cinco séries de duas a quatro repetições e intensidade correspondente a 85 \% e 90 \% de uma repetição máxima ${ }^{(16)}$. Previamente ao início das sessões eram executados quatro a cinco séries de saltos pliométricos em profundidade com plintos com altura de $40 \mathrm{~cm}$. Para o treinamento da força rápida foi utilizado treinamento com pesos executado nas três semanas subseqüentes ao treino de força máxima, em três sessões semanais realizados em dias alternados. Os exercícios foram executados em três séries e dez repetições e intensidade correspondente a 70\% de uma repetição máxima ${ }^{(16)}$. O treinamento de força máxima e força rápida eram compostos pelos mesmos exercícios utilizados no treinamento de resistência de força no M1 e foram realizados em forma de circuito com 60s de intervalo para transição entre os exercícios.

O período competitivo foi subdividido em dois mesociclos de preparação: etapa pré-competitiva e etapa competitiva, respectivamente. A etapa pré-competitiva (M3) foi constituída de um mesociclo com duração de quatro semanas e teve o propósito de desenvolver a velocidade (aceleração, reação e resistência de sprint). O treinamento da velocidade de aceleração e reação foi constituído de corridas máximas de 10, 20 e 30m, com variações na saída (com indivíduos sentados, em decúbito dorsal, apoiados unilateralmente junto às pontas dos pés e com acentuada inclinação a frente), volume crescente a cada semana, com quatro a seis séries de oito a dez repetições. $\mathrm{O}$ intervalo de recu- peração entre as séries foi de 30-90s. Também foram realizados saltos em profundidade com altura de 20 e $40 \mathrm{~cm}$, seguidos de aceleração máxima de 6 a 10m, em três a cinco séries de oito a doze repetições e intervalo entre as séries de 60-90s. 0 treinamento da resistência de sprint foi executado por meio de corridas sub-máximas de curtas distâncias (até $30 \mathrm{~m}$ ) com quatro a cinco séries de seis a dez repetições e intervalo de 10s entre as séries. Todos os treinos de velocidade foram realizados de forma conjunta com os treinos técnicos utilizando situações exigidas no jogo, buscando adaptar os atletas às situações específicas do desporto.

A etapa competitiva (M4) teve duração de dez semanas e objetivou a manutenção dos níveis adquiridos das capacidades físicas de resistência, força e velocidade em todas as suas formas de manifestação. Os microciclos de preparação que compuseram esta etapa foram constituídos de unidades de treinamento complexo que envolveu trabalhos de força e resistência, bem como de treinamento de potência anaeróbia de curta e média duração. Ressalta-se, ainda, que a cada dois microciclos, eram realizados treinamentos para melhoria da capacidade aeróbia.

\section{Análise estatística}

Tendo em vista que a distribuição dos valores de PT e RFE obtidos no presente estudo não apresentaram distribuição normal, foi empregada estatística não-paramétrica. A apresentação dos resultados foi feita por meio de mediana e semi-amplitude interquartílica. A comparação dos valores de RFE obtidos após a etapa de preparação geral entre os indivíduos que concluíram o experimento (G1), e os que deixaram o clube (G2) e foram excluídos por lesão (G3), bem como a comparação entre a RFE dos membros direito e esquerdo nos quatro momentos do estudo (M1, M2, M3 e M4) foi realizada por meio do teste $U$ de MannWhitney. Para a comparação da evolução do PT e RFE em ambos os membros ao longo da temporada foi empregada o teste Friedman para medidas repetidas, seguida do teste de Wilcoxon quando verificados efeitos significantes. A significância estatística adotada foi de $p<0,05$.

\section{RESULTADOS}

O equilíbrio muscular de flexores e extensores de joelho direito (RFED) e esquerdo (RFEE) dos sujeitos que fizeram parte do grupo experimental (G1), dos que deixaram o clube (G2) e dos excluídos por lesão (G3) na etapa de preparação geral do macrociclo de treino (M1) são apresentados na tabela 1. Os valores de RFED e RFEE do G1 não diferiram significativamente dos G2 e G3.

Tabela 1. Equilíbrio muscular de flexores e extensores de joelho direito (RFED) e esquerdo (RFEE) dos sujeitos que fizeram parte do grupo experimental (G1), dos que deixaram o clube (G2) e dos excluído por lesão (G3) na etapa de preparação geral do macrociclo de treino (M1). Valores expressos em mediana \pm semi-amplitude interquartílica.

\begin{tabular}{llll}
\hline & G1 (N=15) & G2 (N=5) & G3 (N=3) \\
\hline RFED (\%) & $63,1 \pm 4,6$ & $62,2 \pm 4,0$ & $61,4 \pm 4,5$ \\
RFEE (\%) & $61,5 \pm 4,8$ & $61,0 \pm 4,5$ & $59,0 \pm 4,0$ \\
\hline
\end{tabular}

Na tabela 2 são apresentados os valores expressos em mediana \pm semi-amplitude interquartílica do PT dos músculos flexores de joelho direito (FLD) e esquerdo (FLE) e extensores do joelho direito (EXD) e esquerdo (EXE) nos diferentes momentos da temporada (M1, M2, M3 e M4).

Houve aumento significante do PT dos FLD e FLE entre o M1 e o M2 (4,0 e 4,4\%; respectivamente), que se manteve entre M1 e M3 (3,5 e 5,0\%; respectivamente), e redução no $M 4$, que apresentou diferenças significantes em comparação a M2 e M3. Quando analisado o PT dos EXD e EXE nos diferentes momentos da temporada, foi constatada redução significante do $\mathrm{M} 1$ para o $\mathrm{M} 2$ (5,5 e 3,7\%; respectivamente), que se manteve constante ao longo da temporada (M1 e M3: 5,1 e 
Tabela 2. Pico de Torque dos músculos flexores de joelho direito (FLD) e esquerdo (FLE), e extensores do joelho direito (EXD) e esquerdo (EXE) nos diferentes momentos da temporada (M1, M2, M3 e M4). Valores expressos em mediana \pm semi-amplitude interquartílica. $(\mathrm{N}=15)$

\begin{tabular}{ccccc}
\hline & M1 & M2 & M3 & M4 \\
\hline FLD (\%MC) & $173,0 \pm 11,0$ & $180,0 \pm 9,0^{*} \dagger$ & $179,0 \pm 8,0^{*}+$ & $170,0 \pm 12,0$ \\
FLE (\%MC) & $161,0 \pm 10,0$ & $168,0 \pm 8,0^{*} \dagger$ & $169,0 \pm 8,0^{*}+$ & $161,0 \pm 12,0$ \\
EXD (\%MC) & $274,0 \pm 12,0$ & $259,0 \pm 10,0^{*}$ & $260,0 \pm 10,0^{*}$ & $256,0 \pm 13,0^{*}$ \\
EXE (\%MC) & $268,0 \pm 11,0$ & $258,0 \pm 10,0^{*}$ & $257,0 \pm 11,0^{*}$ & $251,0 \pm 14,0^{*}$
\end{tabular}

$\mathrm{MC}=$ massa corporal; *Diferença significante em relação ao $\mathrm{M} 1$; $†$ Diferença significante em relação ao $M 4(p<0,05)$.

4,1\%, respectivamente; $M 1$ e M4: 6,6 e 6,3\%, respectivamente). Não foram encontradas diferenças significantes no PT dos EXD e EXE entre M2, M3 e M4 ( $p>0,05)$.

Na tabela 3 são apresentados os valores expressos em mediana \pm semi-amplitude interquartílica da RFE de joelho direito (RFED) e esquerdo (RFEE) nos diferentes momentos da temporada (M1, M2, M3 e M4).

Tabela 3. Equilíbrio muscular de flexores e extensores de joelho direito (RFED) e esquerdo (RFEE) nos diferentes momentos da temporada (M1, M2, M3 e M4). Valores expressos em mediana \pm semi-amplitude interquartílica. $(\mathrm{N}=15)$

\begin{tabular}{ccccc}
\hline & M1 & M2 & M3 & M4 \\
\hline RFED (\%) & $63,1 \pm 4,6$ & $67,4 \pm 5,6^{*}$ & $67,4 \pm 5,03^{*}$ & $66,0 \pm 7,53$ \\
RFEE (\%) & $61,5 \pm 4,8$ & $65,2 \pm 5,6^{*}$ & $65,5 \pm 4,5^{*}$ & $64,1 \pm 4,8$ \\
\hline
\end{tabular}

*Diferença significante em relação ao M1 $(p<0,05)$.

Os resultados da RFED e RFEE indicaram aumento significante entre o M1 e M2 (7\% e 6\%, respectivamente), que foi mantido até M3 (7\% e $6 \%$, respectivamente). Em M4 não foi observada diferenças significantes em comparação aos demais momentos do estudo (M1, M2 e M3), em ambos os membros.

A comparação entre a RFED e RFEE nos diferentes momentos da temporada (M1, M2, M3 e M4) indicaram não existir diferença significante entre os membros nos diferentes momentos da temporada.

\section{DISCUSSÃO}

Grupos adicionais (grupo controle ou outro grupo com organização de MP diferente daquele utilizado no presente estudo) não foram utilizados com o objetivo de contrastar os valores de PT e RFE de joelho, visto que o objetivo deste estudo não foi comparar resultados com outros MP, mas sim, mediante uma razoável e importante validade interna, observar o comportamento da RFE de joelho ao longo de uma temporada de treinamento em jogadores de futebol categoria sub-20, pouco discutido e elucidado no que tange ao conhecimento científico, principalmente neste esporte.

A RFE de joelho tem sido apontada como importante ferramenta para examinar a habilidade funcional das articulações e a instabilidade do ligamento cruzado anterior, e, consequentemente, risco de lesões em atletas ${ }^{(5,6)}$. Além disso, segundo Oliveira et al.(17) a utilização da RFE em atletas permite manipular o treinamento de força durante o MP, possibilitando, assim, melhor adequação entre o treinamento específico da musculatura agonista e antagonista durante a temporada.

Entretanto, os estudos existentes na literatura sobre a RFE no futebol trazem apenas resultados obtidos a partir de análises transversais. Pinto \& Arruda ${ }^{(18)}$ verificaram, em atletas de futebol brasileiros da primeira divisão, RFE de 57,6\%. Sassaki et al. ${ }^{(7)}$, investigando jogadores de futebol brasileiros da primeira divisão, encontraram valores de $65 \%$ e $62 \%$ para RFED e RFEE, respectivamente. Em adição, resultados apre- sentados por Zakas ${ }^{(19)}$, que avaliou um grupo de jogadores de futebol da Grécia, obtiveram RFE de $62 \%$. Esses valores são semelhantes aos encontrado na presente investigação, na qual foram verificados RFE entre $61,5 \%$ e 63,1 \% no M1.

Quando analisados os dados da RFE ao longo da temporada de treinamento, os resultados encontrados no presente estudo demonstraram que existe variação da RFE ao longo da temporada em jogadores de futebol. Os resultados indicaram aumento significante da RFE em ambos os membros após a realização do mesociclo de preparação especial (entre M1 e M2), etapa em que foi enfatizado o treinamento específico de força. Na etapa pré-competitiva (entre o M2 e M3), na qual foi realizado o treinamento de velocidade, houve manutenção dos valores de RFE. Por outro lado, no período competitivo (entre M3 e M4), etapa com o objetivo de manutenção das capacidades adquiridas, houve redução na RFE, que retornou aos valores próximos aos observados em M1. Entretanto, em todas as etapas (M1, M2, M3 e M4) a RFE manteve-se entre $63 \%$ e $67 \%$, valores considerados normais para jogadores de futebol(7).

Esses resultados são semelhantes aos encontrados por Oliveira et al. ${ }^{(17)}$ em atletas saltadores com vara do sexo masculino e feminino, investigados ao longo de um MP dividido em diferentes períodos de treinamento (preparatório, competitivo e transição). Os resultados desse estudo indicaram que as médias de RFE do joelho direito e esquerdo aumentaram ao final do período preparatório e decresceram no período competitivo e transitório em ambos os sexos.

A possível relação existente entre a RFE e o risco de lesões parece estar associada principalmente à co-ativação da musculatura antagonista durante o movimento(20). Segundo Gur et al.(20), o complexo ligamento e grupamentos musculares são responsáveis pela preservação da estabilidade da articulação. Assim, durante a extensão de joelhos em movimentos de cadeia cinética aberta, a contração excêntrica dos músculos flexores de joelho pode prevenir lesões nesta articulação.

É interessante notar que o aumento da RFE entre o M1 e os M2 e M3 observados no presente estudo ocorreu em função do aumento do PT dos flexores de joelho com concomitante redução do PT de extensores de joelho em ambos os membros. Curiosamente, a queda do PT dos extensores de joelho ocorreu logo após o mesociclo em que foi enfatizado o treinamento de força (M2). Não sabemos ao certo os motivos dessa redução, todavia, existem algumas hipóteses para tentar explicar esses achados. A primeira refere-se à maior sobrecarga de treinamento, e, maior utilização dos músculos extensores em comparação aos flexores, devido às exigências específicas da modalidade. A maior sobrecarga de treinamento poderia resultar numa menor janela de adaptação para o desenvolvimento da força nessa musculatura, ao passo que a maior utilização pode ter promovido um processo de fadiga acumulada ao longo do MP, que por sua vez, resultou na redução da força. Outra possível explicação seria que o desenvolvimento da força dos músculos flexores de joelho, por meio de treinamento com pesos, promoveu maior ativação dos músculos flexores de joelho como antagonista. Essa hipótese é reforçada pelos achados de Baratta et al. ${ }^{(21)}$, que verificaram aumento da ativação dos músculos flexores de joelho como antagonistas após a realização de poucas semanas de treinamento com pesos específico para essa musculatura em atletas de basquetebol.

Embora a utilização da RFE seja amplamente utilizada em diferentes populações, a validade deste índice como indicativo de predisposição para lesões ainda é controverso. Dvir (22) relata que a relação existente entre a RFE e lesões deve ser analisada com cautela, pois a maioria dos estudos que encontraram associação positiva neste índice apresentava como falha metodológica a falta de correção da gravidade, o que pode ter influenciado nos resultados destes estudos. Essas informações são reforçadas pelos resultados dos estudos que analisaram a relação da RFE e às lesões, realizando correção da gravidade, os quais não observaram nenhuma relação entre essas duas variáveis ${ }^{(8,23)}$. 
Além disso, para Kannus ${ }^{(8)}$, a comparação de valores de RFE individuais com valores de referência apresentados na literatura não fornece nenhuma ferramenta para o processo de reabilitação. Segundo esse autor, a comparação da RFE entre os membros poderia fornecer um indicativo mais confiável, tanto em indivíduos com problemas crônicos, como no pós-operatório. No presente estudo não foi verificado diferenças significantes entre a RFED e RFEE em nenhum momento do MP. Dessa forma, os resultados encontrados nesta investigação indicam que, apesar da ocorrência de variação da magnitude da RFE em ambos os membros ao longo do MP, essa variação foi semelhante nos membros direito e esquerdo, mantendo assim a proporcionalidade entre os membros.

Uma limitação importante do presente estudo refere-se ao tipo de contração utilizada para o cálculo da RFE. Segundo Aagaard et al.(24), a incorporação da medida de força excêntrica dos flexores do joelho para o cálculo da RFE permite obter um indicativo da capacidade desta musculatura em contrapor a força concêntrica dos extensores de joelho, especialmente em altos níveis de força muscular. Diante disso, esses autores sugerem como parâmetro a ser utilizado no cálculo da RFE, a razão entre a força concêntrica dos extensores de joelho e a força excêntrica dos flexores de joelho. Todavia, Baratta et al. ${ }^{(21)}$ demonstraram que a ação da musculatura de flexores de joelho como antagonista está intimamente relacionada à ação antagonista desse grupamento muscular, ou seja, as ações concêntricas são diretamente proporcionais à capacidade de geração de força excêntrica. Assim, parece que, indiretamente, a medida da força concêntrica fornece um indicativo sobre a força excêntrica.

A principal limitação do presente estudo consiste na ausência de grupo controle. A ausência deste grupo impede atribuir somente ao programa de treinamento utilizado as alterações no desempenho dos testes de força ao longo do tempo. Embora no presente estudo alguns fatores de confusão, tais como: a familiarização aos testes, a realização dos testes nos mesmos horários ao longo do MP e a manutenção da mesma temperatura externa em todas as sessões de testes; tenham sido controlados, é importante que os resultados do presente estudo sejam analisados com cautela em virtude da ausência de grupo controle.

Além disso, é importante ressaltar que o presente estudo possui relativa limitação no tocante à generalização dos resultados, e deve ser analisado tão-somente dentro do contexto do futebol e, ainda, na realidade de uma equipe sub-20 de alto rendimento. Essa problemática está relacionada aos estudos longitudinais "de treinamento desportivo", que, se por um lado são extremamente necessários para um maior entendimento dos fatores relacionados à estruturação do processo de treinamento, por outro, perdem em validade externa,

\section{REFERÊNCIAS BIBLIOGRÁFICAS}

1. Wong P, Hong Y. Soccer injury in the lower extremities. Br J Sports Med 2005; 39: 473-82.

2. Anastasiadis S, Anogeianaki A, Anogianakis G, Koutsonikolas D, Koutsonikola P. Real time estimation of physical activity and physiological performance reserves of players during a game of soccer. Studies Health Technology Information 2004; 98: 13-5.

3. Rahnama N, Reilly T, Lees A. Injury risk associated with playing actions during competitive soccer. $\mathrm{Br}$ J Sports Med 2002; 36: 354-9.

4. Weightman DL, Browne RC. Injuries in eleven selected sports. J Sports Med 1975; 9: 136-41.

5. Li RCT, Maffulli N, Hsu YC, Chan KM. Isokinetic strength of the quadriceps and hamstrings and functional ability of anterior cruciate deficient knees in recreational athletes. Br J Sports Med 1996; 30: $161-4$.

6. Aagaard P, Simonsen EB, Trolle M, Bangsbo J, Klausen K. Isokinetic hamstring/quadriceps strength ratio: influence from joint angular velocity, gravity correction and contraction mode. Acta Physiol Scand 1995; 154: 421-7.

7. Sassaki R, Valquer W, Neves LC, Masheredjian F, Rosan L, Aquino JS, Barros TL. Dados de referência em avaliação isocinética da articulação de joelho em atletas de futebol. In: Anais do XXII Simpósio Internacional de Ciências do Esporte: São Paulo, 1999; 137.

8. Kannus P. Isokinetic evaluation of muscular performance: implications for muscle testing and rehabilitation. Int J Sports Med 1994; 15: S11-8.

9. Terreri AS, Greve MDJ, Amatuzzi MM. Avaliação isocinética no joelho do atleta. Rev Bras Med Esporte 2001; 7: 62-6.

10. Tricoli V, Paulo AC. Efeito agudo dos exercícios de alongamento sobre o desempenho de força máxima. Rev Bras Ativ Fis Saúde 2002; 7: 6-13.

11. Fowles JR, Sale DG, MacDougall JD. Reduced strength after passive stretch of the human plantarflexors. J Appl Physiol 2000; 89: 1179-88

12. Perrin HD. Isokinetic Exercise and Assessment, Champaign: Human Kinetics Publishers, 1993. quando comparados aos estudos fragmentados e transversais, que envolvem geralmente amostras maiores e menos específicas.

Apesar do reduzido número de atletas utilizados na amostra do presente estudo, verifica-se que a amostra em questão faz parte de uma população restrita de difícil utilização em caráter investigatório, pois encontram-se constantemente em treinamento, seguindo um MP e envolvidos em competições. Além disso, no futebol, dificilmente um clube possui um grupo com mais de 25 atletas. Adiciona-se o fato de que ameaças importantes para o estudo, decorrentes de problemas de lesões, faltas, atrasos, mudanças no calendário, saída de atletas, chegada de novos, etc, bem como a resistência por parte de treinadores e preparadores físicos em disponibilizar seus atletas são comuns em estudos dessa natureza.

Stone et al. ${ }^{(25)}$ ressaltam que a maioria dos estudos na Ciência do Desporto, diferentemente da Ciência do Exercício, são longitudinais e envolvem múltiplas sessões de testes e relativamente um número reduzido de sujeitos. No entanto, na opinião dos autores, são os mais valiosos para o desenvolvimento e manipulação do treinamento, dada a inerente análise de uma população especifica e a carência de publicações neste sentido.

Assim sendo, diante todas às dificuldades apresentadas, é salutar admitir a relevância do presente estudo, uma vez realizado de forma integral e fidedigna do desenho experimental proposto, bem como do controle nas quatro diferentes etapas do MP, possibilitando a apresentação e a análise da dinâmica da RFE no âmbito do futebol.

\section{CONCLUSÕES}

Os resultados encontrados na presente investigação sugerem a existência de alterações na magnitude da RFE durante um MP. Contudo, essas alterações mantêm-se dentro da faixa de normalidade preconizada pela literatura. Da mesma forma, a comparação da RFE entre os membros não foi alterada ao longo do MP. Esses resultados sugerem que não existem períodos sensíveis para a ocorrência de lesões em virtude de desequilíbrios musculares ao longo do MP em jogadores de futebol da categoria sub-20.

\section{AGRADECIMENTOS}

Os autores agradecem a Associação Atlética Ponte Preta, da cidade de Campinas, São Paulo, por disponibilizar seus atletas e colaborar na execução deste estudo.

Todos os autores declararam não haver qualquer potencial conflito de interesses referente a este artigo.
13. Kellis E. Tibio Femoral joint forces during maximal isokinetic eccentric and concentric efforts of the knee flexors. Clin Biomech 2001; 16: 229-36.

14. Shephard RJ. Biology and medicine of soccer: an update. J Sports Sci 1999; 17: 757-86.

15. Verkhoshansky YV. Entrenamiento Deportivo - Planificacion y programacion. Barcelona: Ed. Martinez Roca, 1990.

16. KraemerWJ, Ratamess NA. Fundamentals of resistance training: progression and exercise prescription. Med Sci Sports Exerc 2004; 36: 674-88.

17. Oliveira FS, Felipe VAA, Pinto SS. Análise evolutiva dos parâmetros isocinéticos da musculatura flexora e extensora de joelho dos atletas saltadores com vara. Revista de Fisoterapia da UNICID 2004; 3: 7-16.

18. Pinto SS, Arruda CA. Avaliação isocinética de flexores e extensores de joelho em atletas de futebol profissional. Fisioterapia em Movimento 2001; 13: 37-43.

19. Zakas EA. Peak torque of quadriceps and hamstring muscles in basquetball and soccer players of different divisions. J Sports Med Phys Fitness 1995; 35: 199-205.

20. Gur H, Akova B, Punduk Z, Kucukoglu S. Effects of age on the reciprocal peak torque ratios during knee muscle contractions in elite soccer players. Scand J Med Sci Sports 1999; 9: 81-7.

21. Baratta R, Solomonow M, Zhou BH, Letson D, Chuinard R, D'ambrosia R. Muscular coactivation. The role of the antagonist musculature in maintaining knee stability. Am J Sports Med 1988; 16: 113-22.

22. Dvir Z. Isokinetics, muscle testing, interpretation and clinical applications. New York: Churchill Livingstone, 1995.

23. Kannus P. Knee flexor and extensor strength ratios with deficiency of the lateral collateral ligament. Arch Phys Med Rehabil 1988; 69: 928-31.

24. Aagaard $P$, Simonsen EB, Magnusson SP, Larsson B, Dyhre-Poulsen P. A new concept for isokinetic hamstring: quadriceps muscle strength ratio. Am J Sports Med 1998; 26: 231-7.

25. Stone MH, Sands WA, Stone ME. The downfall of sports science in the United States. Strength Cond J 2004; $26: 72-5$ 